\title{
Influence of Uranium and Plutonium on the Atomization of Lanthanides (Eu, Dy) Using GFAAS: Correlation of Data by Reaction Mechanism
}

\author{
Santosh Kumar Gupta*, S.K.Thulasidas, P.J. Purohit, Neelam Goyal, and S.V. Godbole \\ Radiochemistry Division, Bhabha Atomic Research Centre \\ Trombay, Mumbai, India
}

\section{INTRODUCTION}

India has embarked on a threestage nuclear power program, which is based on the utilization of natural uranium as nuclear fuel in the first stage, followed by utilization of plutonium in fast reactors as fuels, and breeding of ${ }^{233} \mathrm{U}$ from ${ }^{232} \mathrm{Th}$ in the second stage, and its utilization in the third stage. Presence of trace elements in nuclear materials significantly affects the nuclear reactor operation and breeding. This is mainly because of adverse changes in neutron economy. As neutrons are primary particles causing nuclear fission, their economy is of utmost importance. Elements like $\mathrm{B}, \mathrm{Cd}$, and some other rare earth elements (REEs) viz. Dy, Eu, Gd, and Sm have very large neutron absorption cross-sections, and their presence results in the loss of neutrons. In order to attain a reliable, safe, and efficient reactor operation, there is a need to monitor and control the trace constituents in nuclear materials prior to their use. It is necessary, therefore, to develop analytical methods for trace metal assay in a wide variety of these samples. Analytical methods based on atomic emission spectrometry (AES) provide simultaneous multi-element analysis but it requires large sample amounts (13 ). The use of ICP as an excitation source for the determination of rare earths in a U matrix after chemical separation is reported in order to avoid spectral interference arising

\footnotetext{
Corresponding autbor.

E-mail: santoshg@barc.gov.in,

santufrnd@gmail.com

Tel:- +91-22-25590636

Fax - +91-22-25505151
}

\begin{abstract}
Studies on the atomization of Dy and Eu directly in a U+Pu and U matrix were carried out using graphite furnace atomic absorption spectrometry (GFAAS). The effect of matrix concentration in the range $0-20 \mathrm{mg} / \mathrm{mL}$ and composition of $\mathrm{Pu}$ in a $\mathrm{U}+\mathrm{Pu}$ matrix in the range $0-100 \% \mathrm{Pu}$ was studied. A continuous constant absorbance was observed for both analytes with a progressive increase in Pu percentage, but the absorbance signal was suppressed (75\% for Dy and $~ 85 \%$ for Eu) with an increase in matrix concentration up to $20 \mathrm{mg} / \mathrm{mL}$ compared to a matrix-free solution.

Therefore, methods were developed for the direct determination of Dy and Eu with a lower matrix concentration of $2 \mathrm{mg} / \mathrm{mL}$ $\mathrm{U}$ and $\mathrm{U}+\mathrm{Pu}$ matrices (suppression is reduced to $50 \%$ for $\mathrm{Eu}$ and $40 \%$ for Dy). Suppression in absorbance in the presence of the matrix was correlated with the atomization mechanism. The atomization mechanism proposed is based on the activation energy calculation using Arrhenius plots.
\end{abstract}

from the volatilization and excitation of major matrix (4). The ICPOES determination of Dy and Eu in table salts after co-precipitation with indium phosphate (5) and in columbite-tantalite minerals are reported by Premadas et al. (6). However, the carrier distillation technique is not effective for the determination of rare earth elements in $\mathrm{U}$ and $\mathrm{Pu}$ matrices, which have comparable volatilization behavior like the $\mathrm{U}$ and $\mathrm{Pu}$ matrices. A report is available for determination of Dy in the sample, using carbon powder, potassium sulfate, barium sulfate, strontium sulfate, and scandium chloride as buffer and scandium as internal standard, by atomic emission spectrometry (AES) (7). An emission spectrographic method for the estimation of rare earth impurities in plutonium oxide and the mixed oxide $(\mathrm{U}, \mathrm{Pu}) \mathrm{O}_{2}\left(30 \% \mathrm{PuO}_{2}\right.$ $70 \% \mathrm{UO}_{2}$ ) is also reported (8).

Atomic absorption spectrometry (AAS) is very widely used in analytical work and has shown its versatile applicability in plutonium, uranium and thorium matrices (911). However, it is still little used for the determination of elements such as lanthanides, scandium, yttrium, and boron. Vaporized at maximum temperatures in the graphite furnace, they exhibit low sensitivity and strong memory effects. It was reported (12) that use of GFAAS as an atomization source for trace metal assay of rare earths in uranium requires development of chemical procedures for the separation of rare earths from a U matrix in order to achieve the required specification limits. However, there is no report available for the determination of these elements in a plutonium matrix. GFAAS has been widely used for the quantitative measurements of Eu and Dy in various matrices such as sheep faeces (13), serum (14), zirconium and calcium rare earth silicate (15), and in rocks (16). There is also one report on the GFAAS determination of Eu (17). Ishizuka et al. (18) investigated the 
effect of inorganic acids, metal ions, and alcohol on the determination of Dy using AAS. However, methods are not yet reported for the direct determination of Eu and Dy in Pu and in U without chemical separation using the GFAAS technique. Hence, it is essential to develop a simple, accurate, and precise method for the determination of traces of Eu and Dy in these nuclear materials without prior separation of $\mathrm{U}$ and $\mathrm{Pu}$ using GFAAS.

The aim of the present studies is the estimation of Dy and Eu in uranium + plutonium and in uranium used as a fuel in a Fast Breeder Test Reactor (FBTR) and pressurized Heavy Water Reactor (PHWR), respectively, using GFAAS. Studies on the direct atomization of Dy and $\mathrm{Eu}$ in $\mathrm{U}+\mathrm{Pu}$ and $\mathrm{U}$ matrices were, therefore, carried out and the effect of matrix on the analyte absorbance was investigated. In addition, the effect of varying amounts of $\mathrm{Pu}$ in $\mathrm{U}$ in the range $0-100 \%$ in a $\mathrm{U}+\mathrm{Pu}$ matrix, the effect of concentration of the $\mathrm{Pu} / \mathrm{U}$ matrix on analyte absorbance, residual accumulation of the matrix in the graphite furnace, and presence of other metallic elements on Dy and Eu absorbance have been investigated. The effect of matrix on analyte absorbance was correlated with the atomization mechanism. These studies have also helped to understand the change in the analyte absorbance signals with the change in the matrix and utilized the results obtained for the direct determination of these analytes in a mixed Pu+U solution using the GFAAS technique.

\section{EXPERIMENTAL}

\section{Instrumentation \\ GFAAS}

To analyze Pu-bearing samples, a Varian Techtron Model AA-6 atomic absorption spectrometer (Varian Techtron, Australia), equipped with a carbon rod atomizer (CRA-63, Mini Massmann), was used. The AAS unit was adapted for radioactive work by modifying the modular setup by placing the isolated atomizer in a glove box environment (9). However, for a glove box-adapted CRA-63 atomizer, temperature measurements were not possible and hence the temperatures given by the manufacturer are being utilized to calculate activation energy $\left(\mathrm{E}_{\mathrm{a}}\right)$ values. To optimize methods in a U matrix, a computercontrolled GBC-906 atomic absorption spectrometer, equipped with a GF 3000 graphite atomizer, was used. A two-color optical pyrometer, Model M/s Reytek (Reytek, USA), sensitive in the range of $1000-3000^{\circ} \mathrm{C}$, was used to measure the temperatures in the atomization stage by focusing the optical pyrometer through the sampling hole, assuming that the black body conditions persist. The set and the measured temperatures were in good agreement. The atomizer was covered with a shield made up of a Perspex ${ }^{\circledR}$ sheet which could be moved when access to the atomizer was necessary. Containment of uranium fumes was ensured through the adequate exhaust system provided around the atomizer. The atomizer unit exhaust was connected to a glove box exhaust system (19). The instrumental parameters used for both analytes, using both instruments, are given in Table I. Argon gas of purity 99.995 vol. \% was used as a purge gas.

Table I Instrumental Operating Parameters for Dy and $E$

\begin{tabular}{lrr}
\hline Parameters & Eu & Dy \\
\hline Wavelength (nm) & 459.4 & 421.2 \\
Spectral Band- & & \\
$\quad$ width (nm) & 0.5 & 0.2 \\
Lamp Fill Gas & $\mathrm{Ne}$ & $\mathrm{Ne}$ \\
Gas used & $\mathrm{Ar}$ & $\mathrm{Ar}$ \\
Flow rate (L/min) & 6 & 6 \\
Lamp current (mA) & 15 & 10 \\
\hline
\end{tabular}

\section{ICP-AES}

A computer-controlled ICP spectrometer SOP consists of a $0.75 \mathrm{M}$ holographic grating with Paschen Runge mounted optics. The argon gas-supported inductively coupled plasma (ICP) source was used for dissociation, atomization, and excitation of the analytes. A peristaltic pump-assisted pneumatic cross flow nebulizer was used for the solution sample introduction into the plasma. A computer-controlled high resolution simultaneous atomic emission system, ICP spectrometer SPECTRO ARCOS SOP with 32 linear arrays of CCD detectors having 3648 pixels per array and a pixel resolution of 3 picometer $(130-340 \mathrm{~nm})$ and 6 picometer (> $340 \mathrm{~nm}$ ), was used for validation of the GFAAS results.

\section{Standards and Reagents}

Eu and Dy working solutions were prepared by appropriate dilution of the standard stock solutions (Eu and Dy, $1 \mathrm{mg} / \mathrm{mL}$ in 5\% nitric acid; CertiPUR ${ }^{\circledR}$ grade from $\mathrm{M} / \mathrm{s}$ Merck, Germany). Details of the preparation of plutonium (200 $\mathrm{mg} / \mathrm{mL}$ ) and uranium $(200 \mathrm{mg} / \mathrm{mL}$ ) were reported earlier from our laboratory (9). To study the matrix effect, a mid-range concentration standard was prepared for Dy and Eu with varying amounts each of $\mathrm{Pu}$ and $\mathrm{U}$ matrix ranging from $0-20 \mathrm{mg} / \mathrm{mL}$. To study the effect of varying amounts of plutonium in the U+Pu matrix, mid-range concentration standards were prepared for Dy $(0.5 \mu \mathrm{g} / \mathrm{mL})$ and $\mathrm{Eu}(0.5$ $\mu \mathrm{g} / \mathrm{mL}$ ) with $\mathrm{Pu}$ ranging from $0-100 \%$, with the overall matrix concentration fixed at $2 \mathrm{mg} / \mathrm{mL}$. After optimizing the matrix proportion for the direct determination of Dy and $\mathrm{Eu}$ in a $\mathrm{Pu} / \mathrm{U}+\mathrm{Pu}$ matrix, a series of standard solutions were prepared for Eu and Dy, each containing $2 \mathrm{mg} / \mathrm{mL} 50 \% \mathrm{Pu} / \mathrm{U}+\mathrm{Pu}$ $(1.0 \mathrm{mg} / \mathrm{mL} \mathrm{Pu}+1.0 \mathrm{mg} / \mathrm{mL} \mathrm{U})$ and $100 \% \mathrm{U}(2.0 \mathrm{mg} / \mathrm{mL})$, with concentrations of Eu and Dy ranging from 
$0.005-0.6 \mu \mathrm{g} / \mathrm{mL}$. To study the effect due to the presence of 21 common metallic elements (Ag, B, $\mathrm{Ba}, \mathrm{Be}, \mathrm{Cd}, \mathrm{Cr}, \mathrm{Cs}, \mathrm{Co}, \mathrm{Cu}, \mathrm{Fe}, \mathrm{Li}$, Mn, Mo, Na, Mg, Ni, Si, Sn, Ti, V and $\mathrm{Zn}$; other than the element of interest) on these two analytes, the standard was also prepared at intermediate concentrations.

\section{Sample Preparation}

In the absence of certified reference materials for Dy and Eu with a $\mathrm{U}$ and $\mathrm{U}+\mathrm{Pu}$ matrix, three synthetic samples of $\mathrm{U}$ and $(\mathrm{U}+\mathrm{Pu})$ were prepared with a matrix $(2 \mathrm{mg} / \mathrm{mL}$ $50 \% \mathrm{Pu} / \mathrm{U}+\mathrm{Pu})$ and graded concentrations of Dy and Eu at 10, 50, and $100 \mathrm{ppm}(\mu \mathrm{g} / \mathrm{g})$, which is equivalent to $0.02,0.1$, and $0.2 \mu \mathrm{g} / \mathrm{mL}$ of Dy and Eu each in $2 \mathrm{mg} / \mathrm{mL}$ $50 \% \mathrm{Pu} / \mathrm{U}+\mathrm{Pu}$ and $100 \% \mathrm{U}$ matrix. These were used as reference samples for obtaining precision and to validate the method developed here.

\section{Procedure}

GFAAS

The fundamental conditions of GFAAS analysis (such as temperature and time durations at pyrolysis and atomization steps) were investigated in order to identify the optimum conditions for obtaining sensitive and stable atomic absorbance signals for Dy and Eu in $50 \% \mathrm{Pu} / \mathrm{U}+\mathrm{Pu}$ and $100 \% \mathrm{U}$ as well as in the matrix-free solution. The detailed procedure adopted here was similar to that followed earlier for trace metal analysis of Ag with and without matrix (9). Dy and Eu absorbance was monitored as a function of (a) matrix concentration in the range $0-20 \mathrm{mg} / \mathrm{mL}$ of each of $50 \% \mathrm{Pu} / \mathrm{U}+\mathrm{Pu}$ and $100 \% \mathrm{U}$ using Dy $(0.5 \mu \mathrm{g} / \mathrm{mL})$ and $\mathrm{Eu}(0.5$ $\mu \mathrm{g} / \mathrm{mL}$ ) concentrations; (b) matrix composition on a fixed concentration of Dy $(0.4 \mu \mathrm{g} / \mathrm{mL})$ and Eu (0.5 $\mu \mathrm{g} / \mathrm{mL}$ ) and varying plutonium proportions in the range $0-100 \%$ $\mathrm{Pu} / \mathrm{U}+\mathrm{Pu}$. Characteristic concentration was obtained for Eu and Dy by analyzing two sets of standards made one each in aqueous, 50\% $\mathrm{Pu} / \mathrm{U}+\mathrm{Pu}$, and $100 \% \mathrm{U}$, with a graded proportion of the analytes.

\section{ICP-AES}

Using the 'ICAL' solution standard supplied by the manufacturer of the instrument (consisting of various elements in specific concentrations), the instrument was evaluated to ensure maximum output for the given known concentration. Then, a method was created to incorporate the analytes with their wavelengths and the lower and higher standard to be used for calibration, followed by calibration of the analytes using the high standard $(10 \mathrm{ppm})$ and a low standard $(0 \mathrm{ppm})$. Following the calibration, the best fit values for each of the analytes were incorporated in the method using the computer software. Finally, the sample solutions were run, and the estimates for each of the analytes were otained.

\section{Separation of Major Matrix}

To utilize the separated samples from the matrix for the determination of these analytes, a mid-range concentration standard was prepared for Dy and Eu with $200 \mathrm{mg}$ of $50 \% \mathrm{Pu} / \mathrm{U}+\mathrm{Pu}$ and $\mathrm{U}$ matrix. For quantitative chemical separation of the analytes, 30\% TBP/dode-cane in $4 \mathrm{M} \mathrm{HNO}_{3}$ was used. To utilize the separated method for the determination of these analytes, it is important to understand the effect of $\mathrm{U}+\mathrm{Pu}$ and $\mathrm{U}$ in raffinate solution on Dy and Eu. Therefore, to study the matrix effect in raffinate solution, a Dy $(0.4 \mu \mathrm{g} / \mathrm{mL})$ and $\mathrm{Eu}(0.4 \mu \mathrm{g} / \mathrm{mL})$ standard was prepared with varying amounts each of $50 \% \mathrm{Pu} / \mathrm{U}+\mathrm{Pu}$ and $\mathrm{U}$ matrix at much lower concentration ranging from $10-500 \mu \mathrm{g} / \mathrm{mL}$.

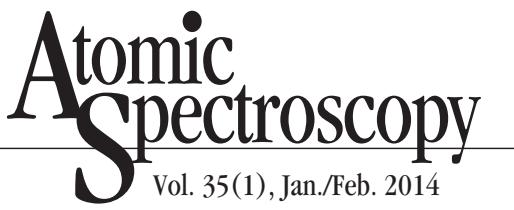

\section{RESULTS AND DISCUSSION}

\section{Optimization of GF Heating Parameters}

Direct atomization of an analyte in the presence of uranium and plutonium matrices in graphite furnace (GF) is influenced by analytematrix, analyte-carbon, and matrixcarbon interactions. The effect of these factors on the atomization of Dy and Eu in matrix-free solutions and matrix were, therefore, carried out extensively. An investigation of the GFAAS measurement parameters, such as pyrolysis temperature, atomization temperatures and time, is very important for achieving precise and sensitive atomic absorbance measurements. For optimization of the GFAAS measurement parameters, effects of the pyrolysis and atomization temperature on the absorbance were investigated in the temperature range of $400-900^{\circ} \mathrm{C}$ and $1900-3000{ }^{\circ} \mathrm{C}$, respectively, for Dy and $\mathrm{Eu}$ in aqueous nitrate solutions. Since the melting and boiling points of oxides are high and thus the possibility of pyrolysis losses was not expected, the pyrolysis temperature is not very critical for these analytes and was optimized at $500{ }^{\circ} \mathrm{C}$. Studies on the atomization behavior in the temperature range of $1700-2800^{\circ} \mathrm{C}$ showed that the optimum temperature for atomization was $2700{ }^{\circ} \mathrm{C}$ for both analytes.

Likewise, the effect of pyrolysis temperature on the absorbance of these analytes was also investigated in the presence of $\mathrm{Pu}$ and $\mathrm{U}$ matrix over a temperature range of 400 to $900{ }^{\circ} \mathrm{C}$. It was found that the absorbance remained constant at and above $700^{\circ} \mathrm{C}$. Using a lower temperature resulted in a strong memory effect. The atomization behavior was studied with the optimized pyrolysis temperature and time duration in the temperature range of 2000 to $3000{ }^{\circ} \mathrm{C}$. A constant and maximum absorbance was obtained at an atomization 
temperature of 2800 to $2900{ }^{\circ} \mathrm{C}$. Possible non-specific absorbance from matrices was examined by atomizing a matrix blank and found to be negligible for both analytes on the optimized parameters. Based on these observations, the pyrolysis and atomization temperatures and time durations were selected for Dy and Eu. In case of the GBC-906, we have facility in our laboratory to keep one intermediate stage ( $1100{ }^{\circ} \mathrm{C}$ for 0.1 second) so that we can improve the ramp rate during the atomization stage. Details of the optimized experimental parameters are listed in Table II. In order to achieve slow and reproducible drying, the dry stage has three steps for the U matrix studies, while such options are not available for $\mathrm{Pu}$ matrix studies.

\section{Effect of Matrix Concentration}

It was reported in the literature (12) that a continuous enhancement in the absorbance signal was observed for Dy and Eu with an increase in $U$ concentration up to $1 \mathrm{mg} / \mathrm{mL}$ matrix, and then a continuous reduction in absorbance up to $7 \mathrm{mg} / \mathrm{mL}$ U. No such studies were carried out on the Pu matrix by the authors. Therefore, studies on the atomization of Dy and Eu in matrixfree solutions as well as in the $\mathrm{Pu} / \mathrm{U}$ matrix were freshly carried out.
The effect of a progressive increase of $\mathrm{U}$ and $\mathrm{Pu}$ concentration was studied using optimized parameters. A continuous reduction in Dy $(0.5 \mu \mathrm{g} / \mathrm{mL})$ and $\mathrm{Eu}(0.5 \mu \mathrm{g} / \mathrm{mL})$ absorbance was observed with an increase in matrix concentrations ranging from $0-20 \mathrm{mg} / \mathrm{mL}$. The variation obtained in the GFAAS absorbance signal of the analytes as a function of increase in $\mathrm{Pu}$ and $\mathrm{U}$ matrix concentration is shown in Figure 1. As can be seen, a significant suppression in absorbance signal was observed with an increase in matrix concentrations ranging from $0-20.0 \mathrm{mg} / \mathrm{mL}$. The suppression in both matrices at $20 \mathrm{mg} / \mathrm{mL}$ was $\sim 75 \%$ for Dy and $\sim 85 \%$ for $\mathrm{Eu}$ in comparison to matrix-free solu- tion. Matrix blank was found to be of the order of reagent blank signal in the range $0-20 \mathrm{mg} / \mathrm{mL}$. This indicated that total suppression in analyte absorbance is due to matrix effects and there are no contributions of the matrix blank. Similar results were obtained for the $\mathrm{U}$ matrix.

Peak profiles for $\mathrm{Eu}(0.5 \mu \mathrm{g} / \mathrm{mL})$ and Dy $(0.5 \mu \mathrm{g} / \mathrm{mL})$ were plotted with and without matrix. Six graphs, three each for Dy and Eu at $0 \mathrm{mg} / \mathrm{mL}$ (matrix free), $2 \mathrm{mg} / \mathrm{mL} \mathrm{U}$, and $20 \mathrm{mg} / \mathrm{mL} \mathrm{U}$ matrix concentrations, are shown in Figure 2.

It can be seen from the graph that peak profiles broaden and peak height reduces with an

TABLE II

Optimized Experimental Parameters for Dy and Eu in the Presence of $50 \% \mathrm{Pu} / \mathrm{U}+\mathrm{Pu}$ and $\mathrm{U}$

\begin{tabular}{|c|c|c|c|c|c|}
\hline \multirow{3}{*}{$\begin{array}{l}\text { Atomizer } \\
\text { Stage }\end{array}$} & \multicolumn{5}{|c|}{ Graphite Furnace Atomizer Settings } \\
\hline & \multicolumn{3}{|c|}{$\begin{array}{l}\text { Uranium } \\
\text { (GBC 906) }\end{array}$} & \multicolumn{2}{|c|}{$\begin{array}{l}\text { Plutonium } \\
\text { (CRA 63) }\end{array}$} \\
\hline & Temp. $\left({ }^{\circ} \mathrm{C}\right)$ & Ramp & Hold & Temp. $\left({ }^{\circ} \mathrm{C}\right)$ & Time (s) \\
\hline \multirow[t]{3}{*}{ Dry } & 80 & 5 & 10 & 150 & 60 \\
\hline & 120 & 10 & 10 & & \\
\hline & 300 & 5 & 10 & & \\
\hline \multirow[t]{2}{*}{ Pre-atomize } & 700 & 0.2 & 10 & 700 & 40 \\
\hline & 1100 & 0.2 & 0.1 & & \\
\hline Atomize & 2850 & 0.9 & 0.5 & 2850 & 3 \\
\hline Cooling & 20 & 14.5 & 10.0 & - & - \\
\hline
\end{tabular}

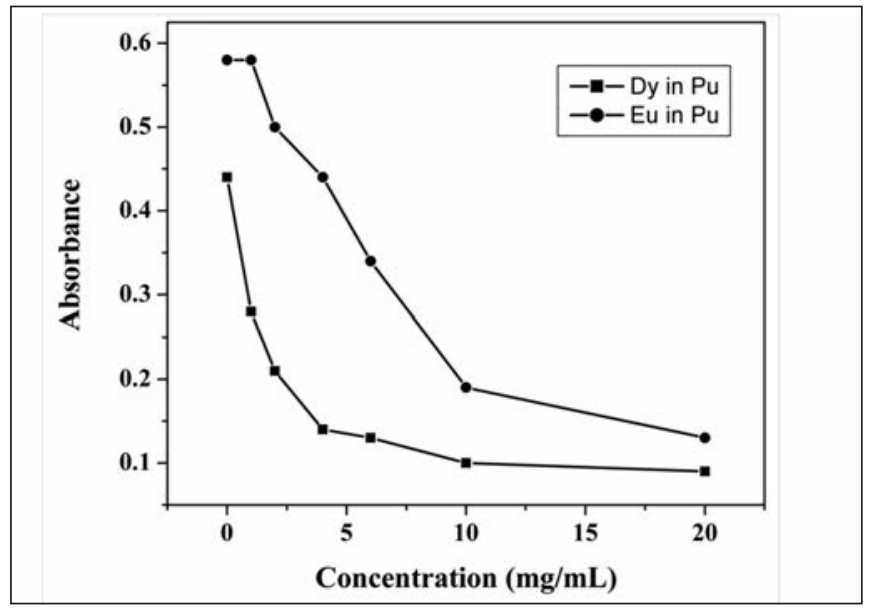

Fig. 1. Effect of Pu matrix concentration on absorbance of Dy and Eu.

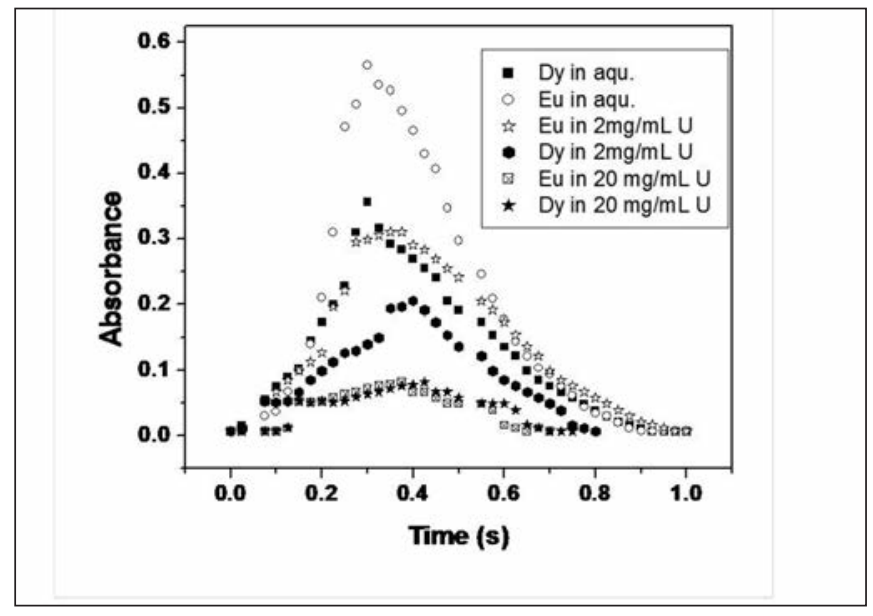

Fig. 2. Peak profiles for Eu and $D y(0.5 \mu \mathrm{g} / \mathrm{mL})$ in the absence and presence of matrix ( 2 and $20 \mathrm{mg} / \mathrm{mL} \mathrm{U}$ ). 


\section{Atomic Apectroscopy \\ 1 Vol. 35(1), Jan./Feb. 2014}

increase in matrix concentration. A large suppression in absorbance profile is seen with high matrix concentrations and, hence, analytical methods for Dy and Eu were developed at lower matrix concentrations $(2 \mathrm{mg} / \mathrm{mL})$. The absorbance suppression in the analytes at $2 \mathrm{mg} / \mathrm{mL}$ was $~ 50 \%$ for $\mathrm{Eu}$ and $40 \%$ for Dy as compared to the matrixfree solution. To analyze Pu-bearing samples, a Varian Techtron Model AA-6 atomic absorption spectrometer was used (which is not a computer-controlled unit) and the peak profile data for the Pu matrix could therefore not be obtained.

\section{Effect of Matrix Composition}

The expected percentage of $\mathrm{Pu}$ in FBTR fuel is $55-66 \%$ and, hence, the effect of matrix composition was studied by varying the plutonium percentage in the uranium matrix from $0-100 \%$ keeping the total matrix concentration as 2.0 $\mathrm{mg} / \mathrm{mL}$ on Dy and Eu $(0.5 \mu \mathrm{g} / \mathrm{mL})$. The variation in GFAAS absorbance signal of Dy and Eu as a function of $\mathrm{Pu}$ percentage in $(\mathrm{Pu}, \mathrm{U})$ matrix is given in Figure 3. A continuous constant absorbance was observed for both analytes with a progressive increase in Pu percentage. In further studies, the $\mathrm{Pu}$ composition was kept at $50 \% \mathrm{Pu} / \mathrm{U}+\mathrm{Pu}$ mixed matrix.
All experimental parameters were optimized again to achieve a maximum $\mathrm{S} / \mathrm{N}$ ratio for Dy and $\mathrm{Eu}$ with $50 \% \mathrm{Pu} / \mathrm{U}+\mathrm{Pu}$ and $100 \% \mathrm{U}$ at $2 \mathrm{mg} / \mathrm{mL}$ matrix concentration and was found to remain the same (see Table II).

To understand suppression in absorbance in the presence of matrix, the atomization mechanism in aqueous, $\mathrm{U}$, and $\mathrm{U}+\mathrm{Pu}$ matrices was studied. The studies so far in the literature are all carried out on analytes with water or weak acids (12), except in a recent work where the reaction mechanism involved in the formation of free analyte atoms with $\mathrm{Zr}$ matrix was given (20). The nature of the reaction mechanism gets significantly altered when atomization of the analytes in the presence of complex matrices such as $U$ and $\mathrm{U}+\mathrm{Pu}$ takes place. The present data deals with the study of the reaction mechanism involved in the atomization of Dy and Eu from $\mathrm{U}$ and $\mathrm{U}+\mathrm{Pu}$ matrices. Activation energy $\left(\mathrm{E}_{\mathrm{a}}\right)$ values were calculated from the Arrhenius plot. The plot of $\log$ absorbance as a function of inverse of the absolute temperature should yield one or more straight lines with slope $=-\mathrm{E}_{\mathrm{a}} / 2.303 \mathrm{R}$, where $\mathrm{R}$ represents the gas constant.
Since construction of a $\log$ Absorbance versus 1/T plot requires that the temperature of the atomic vapor be equal to that of the surface of the furnace, absorbance measurements for $E_{a}$ value calculations were restricted to the initial few hundred milliseconds of the absorption profile (see Figure 4 absorbance - time profile). Absorbance data taken from this region of the curve were used to construct the $\mathrm{E}_{\mathrm{a}}$ plots.

The absorbance signal was obtained for Dy and Eu in aqueous solutions as a function of temperature and the log of absorbance was plotted against inverse of absolute temperature (See Figures $5 \mathrm{a}$ and $5 b)$. The $\mathrm{E}_{\mathrm{a}}$ values were calculated from the slopes of the Arrhenius curves. These plots clearly showed that the mode of atomization for $\mathrm{Eu}$ and Dy seems to essentially remain the same throughout the temperature range since single activation energy values were obtained from these plots. From the $\mathrm{E}_{\mathrm{a}}$ values it appears that dissociation of the metal oxide molecule $\left(\mathrm{Eu}_{2} \mathrm{O}_{3}\right.$ and $\mathrm{Dy}_{2} \mathrm{O}_{3}$ ) is the only mode of atomization. The appearance temperatures $\left(T_{\text {app }}\right.$ is the lowest temperature obtained from the absorbance-timetemperature profile where atomic absorption becomes detectable)

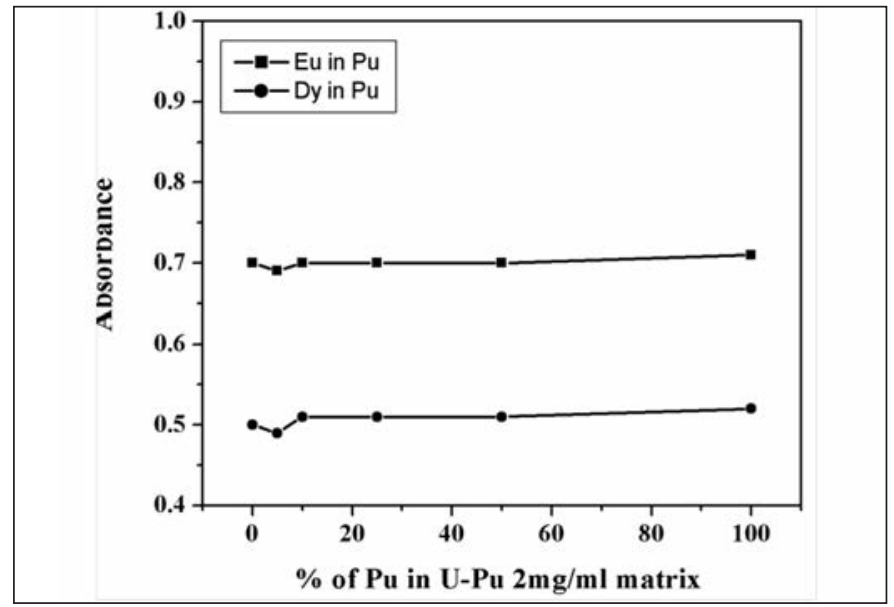

Fig. 3. Effect of varying \% of Pu in mixed matrix on Eu and Dy $(0.5 \mu \mathrm{g} / \mathrm{mL})$.

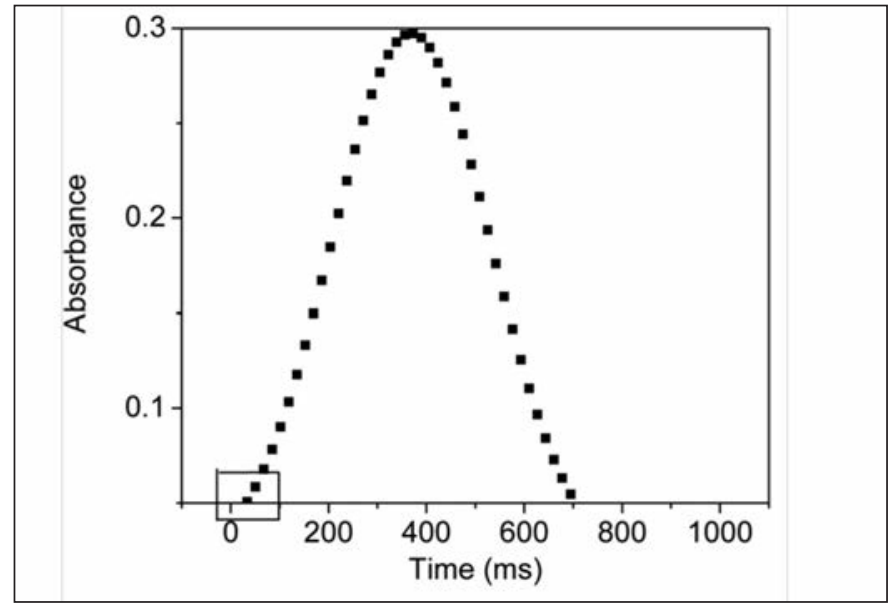

Fig. 4. Typical absorbance-time profile showing the part of the curve from which the data were taken. 
were obtained for both analytes from the absorbance versus time profile. $\mathrm{T}_{\mathrm{app}}$ can give information on whether or not carbothermic reduction is favorable at or prior to $\mathrm{T}_{\text {app }}$. The values of the $\mathrm{T}_{\text {app }}$ obtained (Dy $=2440 \pm 50{ }^{\circ} \mathrm{C}$ and $\mathrm{Eu}=2310 \pm 50^{\circ} \mathrm{C}$ ) are not in accordance with the possible carbothermic reduction of the oxides of Dy and Eu prior to their atomization. It is supported by reported data (21) that carbothermic reduction of $\mathrm{Eu}_{2} \mathrm{O}_{3}$ and $\mathrm{Dy}_{2} \mathrm{O}_{3}$ is unfavorable below appearance temperature. To support our findings of $\mathrm{E}_{\mathrm{a}}$ values, the thermodynamic data were taken from the literature (22) for comparison. The dissociation energy values obtained in our studies was $160.0 \pm 8$ and $145.0 \pm 7$ for the Eu and Dy oxides, respectively, and are rather close to corresponding reported values $\left(\mathrm{Eu}_{2} \mathrm{O}_{3}=\right.$ $134.7 \pm 1.3$ and $\mathrm{Dy}_{2} \mathrm{O}_{3}=150.4 \pm 0.6$ $\mathrm{kcal} / \mathrm{mol}$ ). The reported (12) value for sublimation of the Eu atom after carbothermic reduction of $\mathrm{Eu}_{2} \mathrm{O}_{3}$ is $49.5 \mathrm{kcal} / \mathrm{mol}$. In the present studies, therefore, it is concluded that dissociation of the oxide is the only mode of atomization for both analytes.
From the $\mathrm{E}_{\mathrm{a}}$ energy values, it is implied that the metal oxide was the immediate precursor to the gaseous atom. We can infer that the most probable species available prior to $\mathrm{T}_{\text {app }}$ are $\mathrm{Dy}_{2} \mathrm{O}_{3}(\mathrm{l})$ and $\mathrm{Eu}_{2} \mathrm{O}_{3}(\mathrm{l})$ and, therefore, the sequence of atomization suggested is as follows:

$$
\begin{aligned}
\mathrm{Dy}\left(\mathrm{NO}_{3}\right)_{3} & \rightarrow \mathrm{Dy}_{2} \mathrm{O}_{3}(\mathrm{l}) \rightarrow \mathrm{Dy}_{(\mathrm{g})} \\
\mathrm{Eu}\left(\mathrm{NO}_{3}\right)_{3} & \rightarrow \mathrm{Eu}_{2} \mathrm{O}_{3}(\mathrm{l}) \rightarrow \mathrm{Eu}_{(\mathrm{g})}
\end{aligned}
$$

Having obtained a value of $E_{a}$ and a possible atomization sequence, it is necessary to ensure that the resulting intermediate satisfies physical constants. Here, from $\mathrm{E}_{\mathrm{a}}$ data the oxide in solid state was the precursor to the gaseous atoms. At $\mathrm{T}_{\text {app }}$ the oxides $\mathrm{Dy}_{2} \mathrm{O}_{3(\mathrm{~s})}$ and $\mathrm{Eu}_{2} \mathrm{O}_{3(\mathrm{~s})}$ were in solid state [melting point: $\mathrm{Dy}_{2} \mathrm{O}_{3(\mathrm{~s})}=2340^{\circ} \mathrm{C}$ and $\left.\mathrm{Eu}_{2} \mathrm{O}_{3(\mathrm{~s})}=2291{ }^{\circ} \mathrm{C}(21)\right]$ and once dissociated, they go to gaseous form directly [boiling point: $\mathrm{Dy}=$ $2562{ }^{\circ} \mathrm{C}$ (23) and $\mathrm{Eu}=1439^{\circ} \mathrm{C}$ (23)].

The $\mathrm{E}_{\mathrm{a}}$ plots were similarly obtained in the presence of matrices for Eu and Dy. Figures 6(a) and 7 (a) show log (Abs) vs. 1/T plots for Eu in uranium and uranium+ plutonium matrices, respectively. Figures 6(b) and 7(b) show log (Abs) vs. $1 / \mathrm{T}$ plots for Dy in uranium and uranium+ plutonium matrices, respectively.
The results of these calculations are presented in Table III. Though a better rate of heating $\left(2000{ }^{\circ} \mathrm{C} / \mathrm{s}\right)$ is available in the GF-3000 as compared to the CRA-63 atomizer, the $\mathrm{E}_{\mathrm{a}}$ values for the GF-3000 and CRA63 are almost the same since the $\mathrm{E}_{\mathrm{a}}$ values are independent of the rate of heating of the atomizer (24).

Actually, GFAAS is an analytical technique generally not used to calculate the activation energy. The $\mathrm{E}_{\mathrm{a}}$ values obtained show large variations $(\sim \pm 5 \%)$. The variation is calculated from three different Arrhenius plots.

The mode of atomization and possible intermediate reactions are useful in understanding the possible interference effects in case of complex matrices. It was observed that the slope of the calibration curves obtained for aqueous medium was significantly altered when uranium and plutonium matrices were introduced, suggesting strong matrix influence on the atomization behavior of Eu and Dy. Since signal appearance temperatures and $\mathrm{E}_{\mathrm{a}}$ values remained the same in the aqueous, $\mathrm{U}$, and $\mathrm{U}+\mathrm{Pu}$ matrices for both analytes, the suppression of absorbance in the presence of the $\mathrm{U}$ and $\mathrm{U}+\mathrm{Pu}$ matrices could not be explained from these studies.

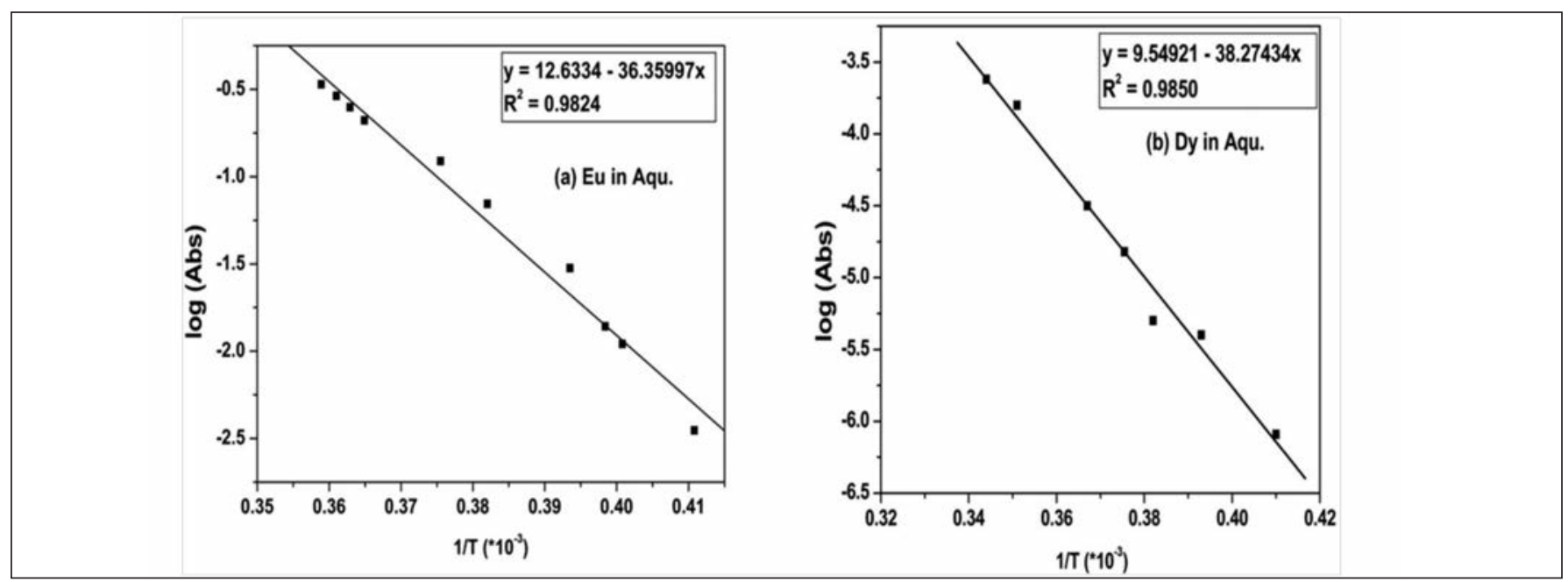

Fig. 5. log (Abs) vs. 1/T for (a) Eu and (b) Dy in aqueous matrix. 


\section{Atomic Spectroscopy \\ $\bigcup$ Vol. 35(1), Jan./Feb. 2014}
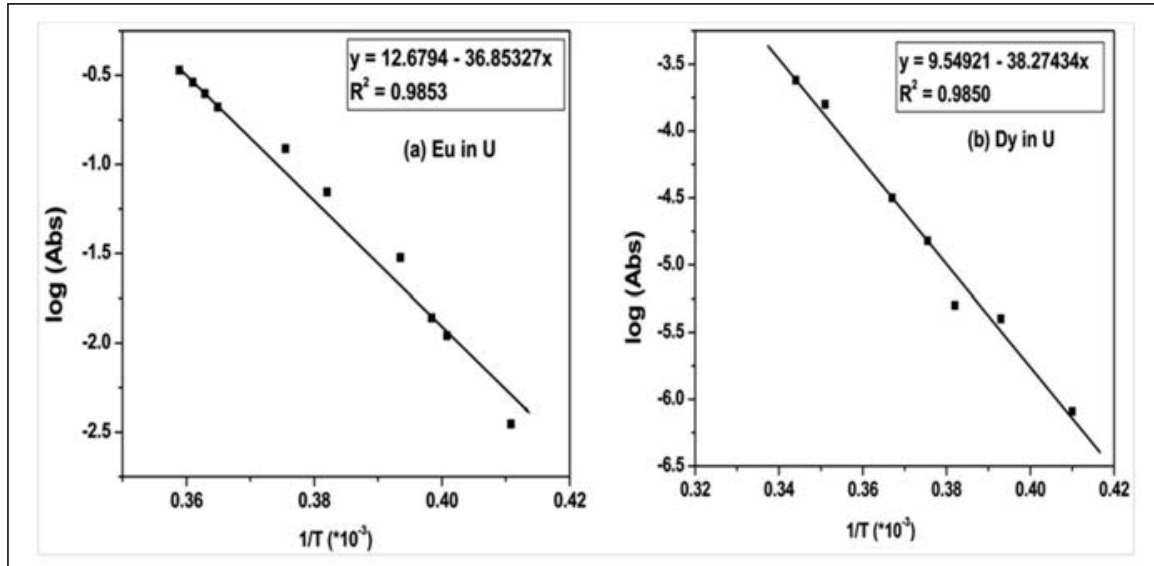

Fig. 6. $\log ($ Abs) vs. 1/T for (a) Eu and (b) Dy in uranium.
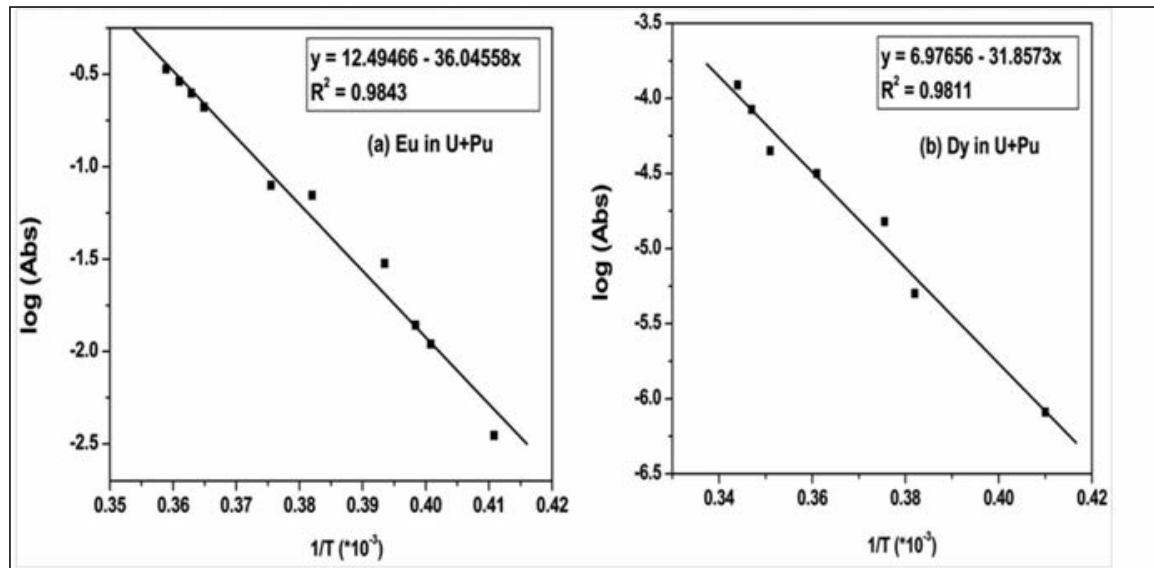

Fig. 7. $\log ($ Abs) vs. 1/T for (a) Eu and (b) Dy in Uranium + plutonium.

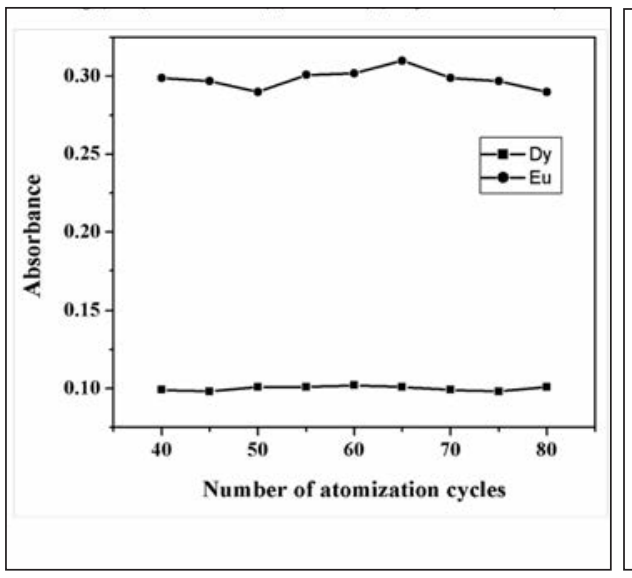

Fig. 8. Effect with accumulation of the $P u+U$ mixed matrix on Dy and Eu.
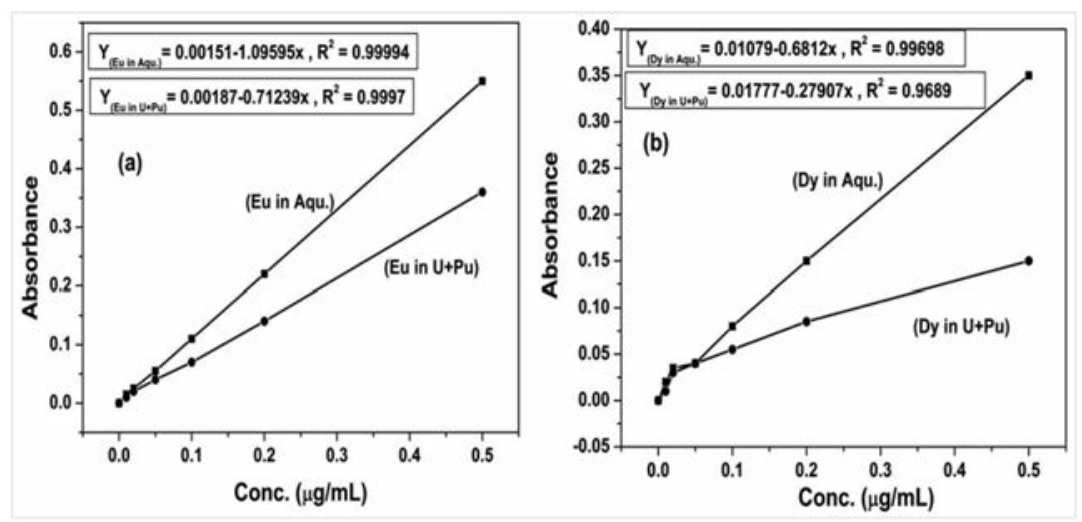

Fig. 9. Analytical curves for Eu and Dy in aqueous and in U+Pu matrix. 
GFAAS provides only indirect information of the atomization process of the analytes occurring in a graphite atomizer. We tried to explain the change in analyte atomization efficiency in the presence of matrix with the dissociation of analyte nitrates, uranyl nitrate/plutonium nitrate (25) (see Equations below).

By the time the system reaches a temperature of $1227^{\circ} \mathrm{C}$, both uranium and plutonium nitrates get converted into their respective dioxides. Both $\mathrm{UO}_{2}$ and $\mathrm{PuO}_{2}$ thus formed are very stable lattices. Similarly, the analytes also get converted into their oxides, mostly dissolved in the main lattice of $\mathrm{UO}_{2}$ and $(\mathrm{Pu}, \mathrm{U}) \mathrm{O}_{2}$. The diffusion rates of cationic elements in these lattices are very low (26-28). A small amount of the analytes dissolved in the $\mathrm{UO}_{2}$ and $(\mathrm{Pu}, \mathrm{U}) \mathrm{O}_{2}$ lattices considerably reduce their chemical activities, hence their detectability, and show a suppression in the absorbance in the presence of these matrices. $\mathrm{UO}_{2}$ and $\mathrm{PuO}_{2}$ dissociate only above $3000{ }^{\circ} \mathrm{C}$,

\begin{tabular}{|l|l|l|l|}
\hline $\mathrm{Eu}\left(\mathrm{NO}_{3}\right)_{3}(\mathrm{~s})$ & $\mathrm{Eu}_{2} \mathrm{O}_{3}(\mathrm{~s})$ & $\begin{array}{l}\text { temperatures than the } \mathrm{T}_{\text {app }} \text { of the } \\
\text { analytes. It is also clear that the } \\
\text { temperature of the atomic vapor }\end{array}$ \\
\hline $\mathrm{Dy}\left(\mathrm{NO}_{3}\right)_{3}(\mathrm{~s})$ & $\mathrm{Dy}_{2} \mathrm{O}_{3}(\mathrm{~s})$ & & \\
\hline $\mathrm{UO}_{2}\left(\mathrm{NO}_{2}\right)_{2}: 6 \mathrm{H}_{2} \mathrm{O}_{(\mathrm{s})} \stackrel{297^{\circ} \mathrm{C}}{\longrightarrow} \mathrm{UO}_{3} \stackrel{757^{\circ} \mathrm{C}}{\longrightarrow} \mathrm{U}_{3} \mathrm{O}_{8(\mathrm{~s})} \stackrel{1297^{\circ} \mathrm{C}}{\longrightarrow} \mathrm{UO}_{2}(\mathrm{~s})$
\end{tabular}

Equations showing change in analyte atomization efficiency in the presence of matrix with the dissociation of analyte nitrates, uranyl nitrate/plutonium nitrate.

TABLE III

Activation Energies of the Atom Formation for Eu and Dy (in aqueous, uranium and $\mathrm{U}+\mathrm{Pu}$ matrixes)

\begin{tabular}{lccccc}
\hline Element & $\begin{array}{l}\text { Appearance } \\
\text { Temp. }\left({ }^{\circ} \mathrm{C}\right) \\
\text { (Remains same in } \\
\text { aqu. and matrices) }\end{array}$ & \multicolumn{3}{c}{$\begin{array}{c}\text { Activation Energy } \\
\text { (Kcal/mol) }\end{array}$} & $\begin{array}{c}\text { Oxide } \\
\text { Dissociation } \\
\text { Energy (21) }\end{array}$ \\
\hline Eu & 2310 & Aqueous & $\mathrm{U}$ & $\mathrm{U}+\mathrm{P}$ & Aqueous \\
Dy & 2440 & $145 \pm 7.5$ & $153 \pm 7.5$ & $160 \pm 8$ & $134.7 \pm 1.3$ \\
\hline
\end{tabular}

did not remain equal to that of the surface of the furnace at higher temperature and hence, the linearity of the Arrhenius plot does not remain at high temperature.

\section{ANALYTICAL RESULTS}

Solutions of $\mathrm{U}$ and $\mathrm{U}+\mathrm{Pu}$ were loaded repeatedly on the same atomizer. Successive loading of $\mathrm{Pu} / \mathrm{U}$ standards and samples leads to a matrix accumulation inside the graphite atomizer. However, this accumulation did not have any significant effect on the Dy and Eu absorbance with repetitive loading of the $2.0 \mathrm{mg} / \mathrm{mL} \mathrm{U}$ matrix on the same atomizer using the GBC-906 with the GF-3000 atomizer. The absorbance remained constant with repetitive loading of the solution for 80 atomization cycles. Similar studies were carried out on the CRA-63 atomizer for a $2 \mathrm{mg} / \mathrm{mL}$ $(50 \% \mathrm{Pu} / \mathrm{U}+\mathrm{Pu})$ matrix. The results did not show any effect on absorbance of Dy $(0.4 \mu \mathrm{g} / \mathrm{mL})$ and $\mathrm{Eu}(0.5 \mu \mathrm{g} / \mathrm{mL})$ with matrix accumulation in the atomizer (Figure 8). However, the atomizer is spoiled fast and can be used for a maximum for 80 atomization cycles.

The degradation in the GF tube may be due to the refractory nature of Eu and Dy as they form stable carbides of these elements. This assumption is based on the fact that for a dysprosium graphite system, according to the data in (29), the vapor phase at temperatures of $2170-2590^{\circ} \mathrm{K}$ consists mainly of dysprosium atoms and $\mathrm{DyC}_{2}$ molecules. Keeping this in view and to increase atomizer life, the atomizer was pre-treated with $\mathrm{Zr}$ and Hf solutions. $\mathrm{Zr} / \mathrm{Hf}$ solutions were dried on the surface of the atomizer prior to loading the Dy/Eu solutions and atomized using optimized parameters. Studies with the $\mathrm{Zr} / \mathrm{Hf}$-coated atomizer did not help to increase the atomizer life. 
Chloride, being more volatile, can improve the sensitivity for these analytes by improving volatilization of the analytes. Studies were also carried out in chloride medium and the effect of chloride ions on analyte absorbance was studied at various molarities of $\mathrm{HCl}$. No improvement in sensitivity was observed with chloride ions either. Therefore, use of $\mathrm{Hf} / \mathrm{Zr}$ coating and $\mathrm{HCl}$ medium was not applied for further studies.

Based on these investigations, two analytical methods for each of the elements, Dy and Eu, were developed for the direct determination of Eu and Dy in 100\% $\mathrm{U}$ and $50 \% \mathrm{Pu} / \mathrm{U}+\mathrm{Pu}$ at $2 \mathrm{mg} / \mathrm{mL}$ matrix using GFAAS. Measurements of the atomic absorption signals for Dy and Eu were carried out over a wide range of concentrations using standard solutions in these matrices. The linear analytical ranges in the presence and absence of matrices were obtained for both analytes. The typical curves with 50\% $\mathrm{Pu} / \mathrm{U}+\mathrm{Pu}$ are shown in Figure 9. The suppression in magnitude of Dy and Eu absorbance was 40\% and $50 \%$, respectively, in the presence of $2 \mathrm{mg} / \mathrm{mL}$ matrix in comparison to a matrix-free solution.

The characteristic concentration values obtained for Dy and Eu in $\mathrm{U}$ and $50 \% \mathrm{Pu} / \mathrm{U}+\mathrm{Pu}$ solution, as evaluated from the calibration plots, are listed in Tables IV and V, along with the analytical ranges and the limit of quantitative determination (LOQD) for Dy and $\mathrm{Eu}$ in aqueous, $50 \% \mathrm{Pu} / \mathrm{U}+\mathrm{Pu}$ and uranium matrix. These analytes showed a reduction in sensitivity in the matrix as compared to aqueous solution but the range of analysis remained the same. These studies also clearly indicate the importance of prior knowledge of the matrix concentration before applying the method for the direct determination of these analytes in $\mathrm{U}+\mathrm{Pu}$ and $\mathrm{U}$ bearing fuels. The data obtained from the above studies reveal that Dy and Eu can be determined at 0.01 $0.5 \mu \mathrm{g} / \mathrm{mL}$ using an aliquot of $5 \mu \mathrm{L}$ sample solution in the presence of a $2.0 \mathrm{mg} / \mathrm{mL} 50 \% \mathrm{Pu} / \mathrm{U}+\mathrm{Pu}$ and $\mathrm{U}$ alone matrices. The analytical methods developed here with $50 \% \mathrm{Pu} / \mathrm{U}+\mathrm{Pu}$ were aimed to apply directly for the analysis of plutonium-bearing fuels in FBTR.

As seen from the Tables IV and $\mathrm{V}$, the characteristic concentration is 1.5 times better with the GF-3000 atomizer as compared to the CRA63. This can be explained on the basis of a better rate of heating $\left(2000^{\circ} \mathrm{C} / \mathrm{s}\right)$ in the GF-3000 as compared to the CRA- 63 . The characteristic concentration in matrix-free solutions is comparable to those reported earlier (12) using the CRA63 unit for Dy and Eu. Such data with matrices (U and $50 \% \mathrm{Pu} / \mathrm{U}+\mathrm{Pu}$ ) were, to our knowledge, not yet

\section{Atomic Spectroscopy 1 Vol. 35(1), Jan./Feb. 2014}

reported in the literature for the analytes Dy and Eu.

The performance of the analytical method was evaluated by analyzing three synthetic samples for each of the analytes prepared from the high purity elemental solution (E-Merck) covering the entire range of analysis with an optimized matrix concentration of $2 \mathrm{mg} / \mathrm{mL}$. Results of the analysis of these samples based on 10 replicate measurements are shown in Table VI and are in good agreement with those expected values. The relative standard deviation calculated from 10 replicate measurements was found to be better than $10 \%$. Deterioration of the GF tube is very fast in the presence of a matrix and leads to irreproducibility of the results. Ten microlitre of xylene loaded prior to each atomization cycle (9)

TABLE IV

Characteristic Concentrations (C.C.) and Analytical Range for Dy in Pu (50\%) and $\mathrm{U}$ Matrices and in Matrix-free Solution

\begin{tabular}{llccccc}
\hline Atomizer & Matrix & \multicolumn{2}{c}{$\begin{array}{c}\text { C. C. }(\mathrm{ng} / \mathrm{mL}) \\
\text { Present }\end{array}$} & \multicolumn{2}{c}{$\begin{array}{c}\text { Linear Analytical } \\
\text { Range }\end{array}$} & LOQD \\
& & & $(12)$ & $(\mu \mathrm{g} / \mathrm{mL})$ & $(\mathrm{ppm}) *$ & $(\mathrm{~g})$ \\
\hline \multirow{2}{*}{ GF-3000 } & Aqueous & 0.003 & - & $0.01-0.5$ & - & $5 \times 10^{-11}$ \\
& $\mathrm{U} 2 \mathrm{mg} / \mathrm{mL}$ & 0.01 & - & $0.01-0.5$ & $5-250$ & $5 \times 10^{-11}$ \\
CRA-63 & Aqueous & 0.005 & 0.005 & $0.01-0.5$ & - & $5 \times 10^{-11}$ \\
& $\mathrm{U} 2 \mathrm{mg} / \mathrm{mL}$ & 0.01 & - & $0.01-0.5$ & $5-250$ & $5 \times 10^{-11}$ \\
& $50 \% \mathrm{Pu} / \mathrm{U}+\mathrm{Pu}$ & & & & & \\
& $2 \mathrm{mg} / \mathrm{mL}$ & 0.01 & - & $0.01-0.5$ & $5-250$ & $5 \times 10^{-11}$ \\
\hline
\end{tabular}

*On the basis of $2.0 \mathrm{mg} / \mathrm{mL}$ of matrix.

TABLE V

Characteristic Concentrations (C.C) and Analytical Range for $\mathrm{Eu}$ in $\mathrm{Pu}(50 \%)$ and $\mathrm{U}$ Matrices and in Matrix-free Solution

\begin{tabular}{|c|c|c|c|c|c|c|}
\hline Atomizer & Matrix & $\begin{array}{l}\text { C. C. (1 } \\
\text { Present }\end{array}$ & $\begin{array}{l}\text { Reported } \\
\text { (12) }\end{array}$ & \multicolumn{2}{|c|}{$\begin{array}{c}\text { Linear Analytical } \\
\text { Range }\end{array}$} & $\begin{array}{c}\text { LOQD } \\
\text { (g) }\end{array}$ \\
\hline \multirow[t]{2}{*}{ GF-3000 } & Aqueous & 0.002 & - & $0.01-0.5$ & - & $5 \times 10^{-11}$ \\
\hline & $\mathrm{U} 2 \mathrm{mg} / \mathrm{mL}$ & 0.006 & - & $0.01-0.5$ & $5-250$ & $5 \times 10^{-11}$ \\
\hline \multirow[t]{3}{*}{ CRA-63 } & Aqueous & 0.003 & 0.003 & $0.01-0.5$ & - & $5 \times 10^{-11}$ \\
\hline & $\begin{array}{l}\mathrm{U} 2 \mathrm{mg} / \mathrm{mL} \\
50 \% \mathrm{Pu} / \mathrm{U}+\mathrm{Pu}\end{array}$ & 0.007 & - & $0.01-0.5$ & $5-250$ & $5 \times 10^{-11}$ \\
\hline & $2 \mathrm{mg} / \mathrm{mL}$ & 0.007 & - & $0.01-0.5$ & $5-250$ & $5 \times 10^{-11}$ \\
\hline
\end{tabular}

*On the basis of $2.0 \mathrm{mg} / \mathrm{mL}$ of matrix. 
improved the reproducibility. A detailed understanding of the role of xylene in this process is impossible from these studies, as they do not throw light on any reaction intermediates. However, it may be preventing the seepage losses through the graphite surface, and may help in obtaining the reproducible results.

The effect due to the presence of 21 common metallic elements (Ag, B, Ba, Be, Cd, Cr, Cs, Co, Cu, $\mathrm{Fe}, \mathrm{Li}, \mathrm{Mn}, \mathrm{Mo}, \mathrm{Na}, \mathrm{Mg}, \mathrm{Ni}, \mathrm{Si}, \mathrm{Sn}$, $\mathrm{Ti}, \mathrm{V}$, and $\mathrm{Zn}$, other than the element of interest) on these two analytes absorbance was studied. These are the elements normally present and required to be determined in the fuel and fuel materials. Presence of these elements at concomitant levels did not show any significant effect on the absorbance signals for Dy and Eu.

It is possible to determine Dy and $\mathrm{Eu}$ in $\mathrm{U}$ and $(\mathrm{U}+\mathrm{Pu})$ matrices successfully using the optimized methods. In view of the high detection limits obtained for these ana- lytes in uranium-plutonium and uranium matrices, the methods are not meeting the specification limits requirement for these analytes in FBTR fuels. The poor atomization efficiency in the presence of $\mathrm{U}+\mathrm{Pu}$ and $U$ is correlated to the entrapment of analytes in the stable lattices of urania and plutonia. Further studies were, therefore, conducted from uranium+plutonium/uranium separated and pre-concentrated solutions using GFAAS.

The results of aqueous samples obtained with the GFAAS GBC-906 were also validated by the ICP-AES Spectro Arcos SOP technique. The fundamental conditions of ICP-AES were investigated in order to identify the optimum conditions for obtaining stable and sensitive signals for Dy and Eu in aqueous solutions. However, ICP-AES suffers from severe spectral interference in the presence of $\mathrm{U}$ and $\mathrm{U}+\mathrm{Pu}$ matrices with a line-rich emission spectrum and, hence, the samples were analyzed only in aqueous solutions. These results are shown in Table VII.

TABLE VI

Analytical Results of Three Synthetically Prepared Samples for the Determination of $\mathrm{Dy}$ and $\mathrm{Eu} \mathrm{ppm}$ in $50 \% \mathrm{Pu} / \mathrm{Pu}+\mathrm{U}$ Matrix

\begin{tabular}{|c|c|c|c|c|}
\hline \multirow[t]{3}{*}{ S. No. } & \multicolumn{3}{|c|}{ Concentration of Spike (ppm) } & \multirow{3}{*}{$\begin{array}{c}\% \mathrm{RSD} \\
\text { (10 replicate measurements) }\end{array}$} \\
\hline & \multirow[t]{2}{*}{ Added } & \multicolumn{2}{|c|}{ Obtained } & \\
\hline & & Dy & $\mathrm{Eu}$ & \\
\hline 1. & 10 & 9.0 & 10.7 & 8 \\
\hline 2. & 50 & 48.5 & 49.4 & 7 \\
\hline 3. & 100 & 105.0 & 100.0 & 4 \\
\hline
\end{tabular}

TABLE VII

Results of Analysis of Four Synthetically Prepared Samples for the Determination of Dy and Eu ppm Using GFAAS from GBC-906 and ICP-AES in Matrix-free Solutions

\begin{tabular}{|c|c|c|c|c|c|c|c|}
\hline \multirow[t]{3}{*}{ S.No. } & \multirow{3}{*}{$\begin{array}{l}\text { Added } \\
(\mu \mathrm{g} / \mathrm{mL})\end{array}$} & \multicolumn{6}{|c|}{ Obtained $(\mu \mathrm{g} / \mathrm{mL})$} \\
\hline & & \multicolumn{3}{|c|}{ GBC 906} & \multicolumn{3}{|c|}{ ICP-AES } \\
\hline & & Dy & $\mathrm{E}$ & $\%$ Variation & Dy & Eu & $\%$ Variation \\
\hline 1. & 0.02 & 0.019 & 0.021 & \pm 0.002 & 0.024 & 0.024 & \pm 0.00048 \\
\hline 2. & 0.1 & 0.11 & 0.10 & \pm 0.01 & 0.11 & 0.11 & \pm 0.0022 \\
\hline 3. & 0.2 & 0.19 & 0.19 & \pm 0.02 & 0.21 & 0.21 & \pm 0.0042 \\
\hline 4. & 0.5 & 0.51 & 0.54 & \pm 0.04 & 0.55 & 0.55 & \pm 0.011 \\
\hline
\end{tabular}

\section{Separation Procedure}

The GFAAS analysis of common metallic elements was previously reported by our laboratory (9) at nanogram and sub-nanogram levels in the presence of plutonium and uranium matrices. To achieve the desired low detection limits at the $0.1 \mathrm{ppm}$ level for these elements, alternate methods were developed which involved chemical separation of the matrix and analysis of raffinate using D.C. arc or ICP-AES (1). Chemical separation procedures based on solvent extraction/ion exchange can be used for this purpose; however, the former procedure, being faster, is preferred. Quantitative chemical separation of the analytes being most essential, detailed studies were carried out to select proper extractants, diluent, and aqueous medium which would facilitate the same. Solvent extraction procedures have been developed using different extractants for the determination of rare earths in plutonium-bearing fuel samples $(8,30)$. However, in the present studies, $30 \% \mathrm{TBP} / \mathrm{CCl}_{4}$ in $4 \mathrm{M} \mathrm{HNO}_{3}$ was used (1) for the separation of the matrix and for analysis.

It was reported (31) that during separation of $1 \mathrm{~g}$ Pu and $\mathrm{U}$, the raffinate contains analytes and a small amount of matrix. The matrix concentration in the raffinate was $\sim 10-50 \mu \mathrm{g} / \mathrm{mL}$. Therefore, to utilize the separated method for the determination of these analytes, it is important to understand the effect of $10-50 \mu \mathrm{g} / \mathrm{mL} \mathrm{Pu}$ and $\mathrm{U}$ in the raffinate on Dy and Eu. Therefore, the effect of $50 \% \mathrm{Pu} / \mathrm{U}+\mathrm{Pu}$ and $\mathrm{U}$ on these analytes was also studied at much lower concentrations of $10-500 \mu \mathrm{g} / \mathrm{mL}$. It was observed that the Dy and Eu absorbance remained unaffected with an increase in matrix concentration ranging from $10-500 \mu \mathrm{g} / \mathrm{mL}$. In order to achieve the desired detection limits (8) of $0.1 \mathrm{ppm}$ for these elements, methods were developed using $200 \mathrm{mg} \mathrm{U}+\mathrm{Pu}$ and U samples 
after chemical separation using $30 \% \mathrm{TBP} /$ dodacane in $4 \mathrm{M} \mathrm{HNO}_{3}$. The chemical separation was applied four times using 30\% TBP/ dodacane in $4 \mathrm{M} \mathrm{HNO}_{3}$ for near total removal of the matrix. The detection limits obtained using this method were $0.05 \mathrm{ppm}$ for both Dy and Eu.

\section{CONCLUSION}

The studies showed that the absorbance signal for Dy and Eu kept decreasing with an increase in matrix concentration ranging from 0-20 mg/mL Pu. The matrix concentration was optimized to $2 \mathrm{mg} / \mathrm{mL}$. Reduction in absorbance was as high as $40-50 \%$ at $2 \mathrm{mg} / \mathrm{mL}$ for both analytes as compared to the matrix-free solution. To use the method for uranium-plutonium mixed oxide samples, the effect of varying concentrations of $\mathrm{Pu}$ in a $\mathrm{U}+\mathrm{Pu}$ mixed matrix was studied. The results showed an absorbance signal of $0-100 \% \mathrm{Pu}$ in a $(\mathrm{Pu}+\mathrm{U})$ mixed matrix with $2 \mathrm{mg} / \mathrm{mL}$ total matrix. Dy and Eu can be determined by GFAAS in $50 \% \mathrm{Pu} / \mathrm{Pu}+\mathrm{U}$ and uranium ranging from $0.02-0.5 \mu \mathrm{g} / \mathrm{mL}$.

Though these methods are not suitable for the determination of Dy and Eu directly in FBTR fuels due to stringent specification limits, attempts were made to understand the plutonium and uranium effect on analyte absorbance and the reaction involved in the atomization of these analytes in the matrices. These methods are suitable to determine Dy and Eu after sorting the chemical separation methods.

\section{ACKNOWLEDGMENT}

The authors are grateful to Dr. Ashok Goswami, Head Radiochemistry Division, for his keen interest and constant encouragement in the course of this work.

Received July 9, 2013.

\section{REFERENCES}

1. M. Kumar, M. Mohapatra, Paru J. Purohit, S. K. Thulasidas, T. K. Seshagiri, N. Goyal, and S.V. Godbole, At. Spectrosc. 31, 97 (2010).

2. V.C. Adya, S.K. Thulasidas, M. Kumar, P.J. Purohit, M. Mohapatra, T. Seshagiri, and S.V. Godbole, Radiochim. Acta 99, 581 (2011).

3. B. Rajeshwari, B.A. Dhawale, T.K. Seshagiri, P.J. Purohit, N. Goyal, and A.G. Page, J. Ind. Chem. Soc. 83, 1 (2006).

4. T. K. Seshagiri, Y. Babu, M.L. Jayantkumar, A.G.I. Dalvi, M.D. Sastry, and B.D. Joshi, Talanta 31, 773 (1984).

5. S. Kagaya, T. Mizuno, and K. Tohda, Talanta 79, 512 (2009).

6. A. Premadas, V. V. Hanuman, and V.N. Dwivedi, At. Spectrosc. 25, 70 (2004).

7. H.Z. Li, D.T. Zhai, J. Zhang, M.S. Pei, Guang Pu Xue Yu Guang and $\mathrm{Pu}$ Fen Xi, Spectroscopy and Spectral Analysis 25, 1500 (2005).

8. A.G. I. Dalvi, C. S. Deodhar, and B. D. Joshi, Talanta 24,143 (1977).

9. N. Goyal, P. J. Purohit, S.K. Gupta, and S.V. Godbole, At. Spectrosc. 32, 206 (2011).

10. P.J. Purohit, N. Goyal, and S.V. Godbole, At. Spectrosc. 32, 68 (2011).

11. S.K. Gupta, N. Goyal, and S.V. Godbole, At. Spectrosc. 32, 107 (2011).

12. M.D. Sastry, M.K. Bhide, K. Savitri, Y. Babu, and B.D. Joshi, Fresenius J. Anal. Chem. 298, 367 (1979).

13. J.C.J. Silva, E.E. Garcia, A.R.A. Nogueira, and J.A.Nóbrega, Talanta 55, 847 (2001).

14. E. Knutsen, G. Wibetoe, and I. Martinsen, J. Anal. At. Spectrom. 10, 757 (1995).

15. J.C. Van Loon, J.H. Galbraith, and H.M. Aarden, Analyst 96, 47 (1971).

16. J.G. Gupta, Talanta 28, 31 (1981).

17. J. Komarek and M. Ganoczy, Collect. Czech. Chem. Commun. 56, 764 (1991).
18. T. Ishizuka and $H$. Sunahara, Anal. Chim. Acta 66, 343 (1973).

19. N. Goyal, P.J. Purohit, and S.V. Godbole, At. Spectrosc. 31, 190 (2010).

20. P.J. Purohit, N. Goyal, and S.V. Godbole, At. Spectrosc. 33, 100 (2012).

21. I. Barin, Thermochemical data of pure substances, IIIrd Edition, Volume 1, John Wiley \& Sons, NY, USA (1995).

22. L. L. Ames, P. N. Walsh, and David White, J. Phy. Chem. 71, 2707 (1967).

23. CRC Handbook of Chemistry and Physics, Ed. By R. C. Weast and published by Chemical Rubber Company, Ohio, USA (1971-72).

24. R.E. Sturgeon and C.L. Chakraborty, Prog. Anal. At. Spectrosc., 140 (1978).

25. N. Goyal, R. Agarwal, P. J. Purohit, and S.V. Godbole, J. Nucl. Mater. 376, 119 (2008).

26. T.A. Lauritzen, P.E. Novak, and J.H. Davies, USAEC Report GEAP-4466, General Electric Company (March 1966).

27. H.J. Matzke, J Nucl. Mater. 114, 121 (1983).

28. D.G. Leme and H.J. Matzke, J. Nucl. Mater. 106, 211 (1982).

29. B. V. L'vov, L. A. Pelieva, and I. Novotny, J. Appl. Spectrosc. 35, 954 (1981).

30. S.K. Thulasidas, V. C. Adya, Mithlesh Kumar, T. K. Seshagiri, and S.V. Godbole, At. Spectrosc. 32, 228 (2011).

31. M.J. Kulkarni, A. A. Argekar, J. N. Mathur, and A.G. Page, Anal. Chim. Acta 370, 163 (1998). 